\title{
Modernização agrícola, agricultura familiar e pluriatividade: um estudo de caso em Canápolis, $\mathbf{M G}^{\bullet}$
}

Carlos Alves do Nascimento*

Samantha Rezende Mendes*

RESUMO - O artigo apresenta algumas conclusões de uma pesquisa de campo realizada com agricultores familiares do município de Canápolis, pertencente ao Triângulo Mineiro e Alto Paranaíba - TMAP. Defende-se que a agricultura familiar do município pesquisado encontrase fragilizada em importantes aspectos, configurando-se uma possível tendência ao abandono das atividades agrícolas e, por tal razão, comprometendo a conformação de casos de famílias pluriativas entre a agricultura familiar do município em questão.

Palavras-chave: Agricultura familiar. Pluriatividade. Modernização. Canápolis.

\section{INTRODUÇÃO}

O objetivo deste artigo consiste em apresentar algumas conclusões de uma pesquisa de campo realizada no município de Canápolis, pertencente ao estado de Minas Gerais. Essa pesquisa procurou entender as razões que fazem com que um determinado conjunto de unidades familiares "resistam" aos efeitos da modernização da agricultura (que tem impacto negativo sobre o emprego agrícola e sobre os pequenos produtores familiares), como é o caso das famílias estritamente agrícolas (não pluriativas), que residem nas mesmas localidades e contam com as mesmas características sociais e culturais das famílias pluriativas ${ }^{1}$. Adicionalmente, procurou-se analisar se a modernização do setor leva a família agrícola a se tornar, tendencialmente, família pluriativa ou família não agrícola. Assim como também analisar se a pluriatividade constitui-se em uma estratégia da família para manter-se no meio rural e na atividade agrícola ou se ela decorre de uma necessidade, em razão da ausência de alternativas (apoio estatal) para agricultura, configurando-se ou não como um passo transitório para as famílias se converterem de vez em famílias não agrícolas.

\footnotetext{
- Os autores agradecem o apoio do CNPq (Processo Nr. 479430/2007-1) e da FAPEMIG (Convênio F-0388) para a realização da pesquisa de campo da qual resultou este artigo.

* Professor Doutor do Instituto de Economia da Universidade Federal de Uberlândia (UFU). Endereço eletrônico: can@ie.ufu.br.

** Pesquisadora de Iniciação Científica $(\mathrm{CNPq})$ do Instituto de Economia da Universidade Federal de Uberlândia (UFU). Endereço eletrônico: samantha86_rezende@yahoo.com.br.

${ }^{1}$ Famílias pluriativas são aquelas que conciliam entre seus membros atividades agrícolas e não agrícolas (pluriatividade).
} 
As hipóteses com as quais se trabalhou foram: i) a modernização agrícola e o avanço de monoculturas, a exemplo da cana-de-açúcar, podem estar forçando muitos pequenos produtores familiares a abandonar suas atividades agrícolas; e ii) programas oficiais como, por exemplo, o Programa Nacional de Fortalecimento da Agricultura Familiar - PRONAF, podem estar servindo como fatores atenuantes da hipótese anterior.

Localizado na mesorregião do Triângulo Mineiro e Alto Paranaíba (TMAP), o município de Canápolis ocupa uma área de $845,24 \mathrm{~km}^{2}$, com uma população de 11.313 habitantes. A principal fonte de renda do município provém da atividade agropecuária diversificada, com destaque para a produção de abacaxi e cana-de-açúcar.

Obtivemos os nomes dos produtores rurais de Canápolis junto a instituições tais como: Sindicato dos Produtores Rurais de Canápolis, Cooperativa dos Produtores de Abacaxi de Canápolis, Instituto Mineiro de Agropecuária e Secretaria Municipal de Agricultura. Chegamos a uma relação final de nomes de 243 produtores rurais (após excluídos os nomes repetidos nas diferentes listas e aqueles que logramos saber ex ante que eram proprietários com mais de 120 hectares). Considerou-se amostra aleatória simples e inferiu-se um número de 65 produtores para compor a amostra da pesquisa, correspondendo a 27,0\% do total dos nomes da lista. O dimensionamento da amostra foi realizado com base no cálculo de proporções, utilizando-se o fator de correção de população finita. Sortearam-se os nomes de 4 em 4 ao longo da lista obtida.

\section{ANÁLISE DOS RESULTADOS DA PESQUISA DE CAMPO}

Do total da amostra de 65 famílias, apenas 43 delas compuseram o conjunto da agricultura familiar pesquisada. Consideramos agricultura familiar apenas as famílias de empregadores com até dois empregados ou famílias de conta-próprias, ambos os tipos agrícolas e ou pluriativas - e com estabelecimentos de no máximo 120 hectares.

As famílias pluriativas tanto na amostra total (65 famílias), quanto na amostra específica da agricultura familiar (43 famílias), correspondem à maior fração $(60,0 \%)$ do conjunto dos diferentes tipos de famílias (Tabela 1). Essa informação justifica nosso interesse maior sobre esse tipo familiar, embora nos ocupemos também do conjunto das famílias estritamente agrícolas, uma vez que nos importa inferir sobre as perspectivas desse tipo familiar vir a se tornar família pluriativa, ou permanecer apenas como família agrícola, ou ainda a vir a se converter diretamente em família não agrícola. 
Do conjunto da agricultura familiar da nossa amostra (43 famílias), 55,8\%

famílias) produzem em estabelecimentos com até 10 hectares. Ou seja, mais da metade do universo da agricultura familiar entrevistada trabalha em estabelecimentos rurais relativamente pequenos, para os padrões brasileiros. Se considerarmos apenas as famílias pluriativas, 17 dessas famílias (39,5\% das 43 unidades familiares) produzem em estabelecimentos com até 10 hectares.

TABELA 1: DISTRIBUIÇÃO DOS TIPOS DE FAMÍLIAS DA AGRICULTURA FAMILIAR, SEGUNDO A POSIÇÃO NA OCUPAÇÃO E O RAMO DE ATIVIDADE: CANÁPOLIS, MG, 2008.

\begin{tabular}{|c|c|c|c|c|}
\hline TIPO DE FAMÍLIA & & Nr Fam. & \begin{tabular}{c|} 
\% Famílias \\
(Pos. Ocup.)
\end{tabular} & $\begin{array}{l}\text { \% Famílias } \\
\text { (Ramo Ativ.) }\end{array}$ \\
\hline \multirow[t]{3}{*}{ Empregador com até 2 empregados } & & 9 & 20,9 & \\
\hline & Agrícola & 3 & & 7,0 \\
\hline & Pluriativo & 6 & & 14,0 \\
\hline \multirow[t]{3}{*}{ Conta-próprias } & & 34 & 79,1 & \\
\hline & Agrícola & 14 & & 32,6 \\
\hline & Pluriativo & 20 & & 46,5 \\
\hline TOTAL & & 43 & 100,0 & 100,0 \\
\hline
\end{tabular}

FONTE: Dados coletados na pesquisa de campo e elaborados pelos autores.

Ademais, $60,0 \%$ da agricultura familiar entrevistada não é proprietária das terras em que trabalham (Tabela 2). Se observarmos apenas as unidades familiares que trabalham em estabelecimentos com até 10 hectares de área (24 famílias), aquela proporção aumenta para $88,0 \%$.

TABELA 2: DISTRIBUIÇÃO ABSOLUTA E RELATIVA DA AGRICULTURA FAMILIAR, SEGUNDO FAIXAS DE TAMANHO DE ÁREA E A CONDIÇÃO DO PRODUTOR: CANÁPOLIS, MG, 2008.

\begin{tabular}{|c|c|c|c|c|c|c|c|c|c|c|}
\hline \multirow[b]{2}{*}{$\begin{array}{c}\text { Condição do } \\
\text { produtor }\end{array}$} & \multicolumn{2}{|c|}{0 até 90 hectares } & \multicolumn{2}{|c|}{0 até 50 hectares } & \multicolumn{2}{|c|}{0 até 30 hectares } & \multicolumn{2}{|c|}{0 até 20 hectares } & \multicolumn{2}{|c|}{0 até 10 hectares } \\
\hline & $\begin{array}{c}\mathrm{Nr} \\
\text { Fam. }\end{array}$ & $\%$ & $\begin{array}{c}\mathrm{Nr} \\
\text { Fam. }\end{array}$ & $\%$ & $\begin{array}{c}\mathrm{Nr} \\
\text { Fam. }\end{array}$ & $\%$ & \begin{tabular}{|c|}
$\mathrm{Nr}$ \\
Fam.
\end{tabular} & $\%$ & \begin{tabular}{|c|}
$\mathrm{Nr}$ \\
Fam.
\end{tabular} & $\%$ \\
\hline Proprietário & 17 & 40 & 11 & 30 & 6 & 19 & 3 & 12 & 3 & 13 \\
\hline Arrendatário & 26 & 60 & 26 & 70 & 25 & 81 & 23 & 88 & 21 & 88 \\
\hline Total & 43 & 100 & 37 & 100 & 31 & 100 & 26 & 100 & 24 & 100 \\
\hline
\end{tabular}

NOTA: O tamanho máximo dos estabelecimentos da agricultura familiar pesquisada é de 90 hectares.

FONTE: Dados coletados na pesquisa de campo e elaborados pelos autores.

Em outras palavras, além de parte significativa do universo da agricultura familiar pesquisada trabalhar em estabelecimentos relativamente pequenos, parte também significativa destas unidades familiares são de não proprietários. Essa informação reforça a hipótese de trabalho que aponta para uma situação de latente tendência dos pequenos produtores familiares a abandonarem as (ou a serem expulsos das) atividades agrícolas, em parte, por terem pouco acesso à terra e, por outra parte, por dependerem de possibilidades, não necessariamente asseguradas, de renovação dos contratos (formais ou informais) de arrendamento das propriedades em que exercem os trabalhos familiares. 
Analisou-se também os diferentes tipos de famílias segundo faixas de tamanho de área dos estabelecimentos, incluindo um indicador de nível tecnológico ${ }^{2}$. Esse indicador foi construído para medir o grau de intensidade de envolvimento do produtor rural com melhorias para elevar a produtividade do estabelecimento. Quanto mais próximo de zero ou mais próximo de 1 , a possibilidade da unidade familiar ser produtiva - e, portanto, mais apta ao mercado - será menor ou maior, respectivamente.

Entre os não proprietários, $31,0 \%$ deles são famílias de conta-próprias (agrícolas e pluriativas) com menos de 5 hectares de terra e apresentando indicador de nível tecnológico abaixo da média (no máximo 0,43). Considerando o índice do indicador tecnológico de 0,57 (ou seja, um pouco acima da média) e estabelecimentos com até 10 hectares, compreende-se 61,5\% (ou 16 familias) das unidades familiares de não proprietários.

Essas 16 famílias - com pouca terra para produzir, não proprietárias e com reduzido grau de envolvimento com melhorias tecnológicas nos estabelecimentos - constituem 37,2\% do conjunto da agricultura familiar total da amostra pesquisada. Ou seja, mais de um terço da agricultura familiar pesquisada, em sua maioria famílias pluriativas, apresenta características que apontam para sua fragilidade em permanecer na atividade agrícola como fonte de geração de renda.

Entre as unidades familiares proprietárias, nota-se que a situação não é tão melhor do que a das unidades não proprietárias. Quase um terço $(27,3 \%)$ das unidades familiares proprietárias têm no máximo 10 hectares de terra e o indicador de nível tecnológico não é melhor do que para os produtores não proprietários.

Além disso, das 24 famílias com até 10 hectares de terra, 18 delas (75,0\%, que também corresponde a 48,6\% das 37 famílias com até 50 hectares de terra) declararam ter tido acesso a algum tipo de crédito (Tabela 3). Ou seja, as unidades familiares mais fragilizadas são as que mais recorreram ao crédito bancário. Isso é compreensível porque são as que têm menos recursos próprios para produzir. Estas famílias tiveram acesso aos recursos exclusivamente do PRONAF. Dadas as características de fragilidade já apontadas, percebe-se que o PRONAF pode estar representando uma importante fonte de apoio para os pequenos produtores contornarem aquelas fragilidades e lograrem permanecer resistindo às adversidades do setor, preservando sua identidade de agricultor, sem abandoná-la.

\footnotetext{
2 O indicador foi construído com base nas respostas 'sim' ou 'não' sobre se no estabelecimento o produtor usa assistência técnica, tração mecânica, se aduba o solo, se faz correção do solo (calcário), se faz análise do solo, se usa sementes certificadas, se tem energia elétrica para beneficiamentos. Somou-se essas variáveis e dividiu-se pelo número delas, obtendo uma variação entre 0 e 1 para os diferentes estabelecimentos.
} 
TABELA 3: DISTRIBUIÇÃO DO NÚMERO DE FAMÍLIAS DA AGRICULTURA FAMILIAR (COM ATÉ 50 HECTARES) QUE TIVERAM ACESSO A ALGUMA MODALIDADE DE CRÉDITO BANCÁRIO (PRONAF E OU OUTRA FONTE), SEGUNDO A POSIÇÃO NA OCUPAÇÃO, O RAMO DE ATIVIDADE E FAIXAS DE TAMANHO DE ÁREA: CANÁPOLIS, MG, 2008.

\begin{tabular}{|c|c|c|c|c|}
\hline \multicolumn{5}{|c|}{ PRONAF } \\
\hline \multirow{2}{*}{$\begin{array}{l}\text { Faixas de Área } \\
\text { (Em Hectares) }\end{array}$} & $\begin{array}{c}\text { Empregador com até } 2 \\
\text { empregados }\end{array}$ & \multicolumn{3}{|c|}{ Conta-próprias } \\
\hline & $\begin{array}{l}\text { Pluriativos } \\
\text { (Nr Fam.) }\end{array}$ & $\begin{array}{l}\text { Agrícolas } \\
\text { (Nr Fam.) }\end{array}$ & $\begin{array}{l}\text { Pluriativos } \\
\text { (Nr Fam.) }\end{array}$ & \\
\hline De 0 até 5 & & \multicolumn{2}{|c|}{4} & 11 \\
\hline Mais de 5 até 10 & \multicolumn{3}{|c|}{1} & 2 \\
\hline Mais de 10 até 20 & \multicolumn{3}{|c|}{1} & 1 \\
\hline Mais de 20 até 30 & & \multicolumn{2}{|c|}{2} & \\
\hline \multicolumn{5}{|c|}{ PRONAF e ou outras fontes de Crédito } \\
\hline De 0 até 5 & & & & 11 \\
\hline Mais de 5 até 10 & \multicolumn{2}{|c|}{1} & & 2 \\
\hline Mais de 10 até 20 & \multirow{2}{*}{\multicolumn{2}{|c|}{1}} & & 1 \\
\hline Mais de 20 até 30 & & & & 1 \\
\hline Mais de 30 até 50 & \multicolumn{2}{|c|}{1} & & \\
\hline
\end{tabular}

FONTE: Dados coletados na pesquisa de campo e elaborados pelos autores.

Observou-se que 58,0\% do total das 118 pessoas - entre as famílias com até 10 hectares de terra - com 10 anos ou mais de idade têm 25 anos ou mais (considerando todas as faixas de idade posteriores) e que não têm o $2^{\circ}$ grau completo. A baixa escolaridade da maior fração de pessoas analisadas significa um dificultador para que estas pessoas possam se inserir no mercado de trabalho assalariado e que, portanto, pode ser um elemento que dificulte o abandono das atividades agrícolas, por razões de maiores exigências de escolarização por parte do mercado de trabalho. Jovens e adultos alegavam nas entrevistas dificuldade de inserção no mercado de trabalho, em virtude da pouca oferta de oportunidades ocupacionais, mas também devido à sua baixa escolarização, e, por esta razão, sentiam-se forçados a continuar na "lida do campo", esperando dias melhores na agricultura.

Outros entrevistados apontavam como dificultador para abandonar as atividades agrícolas - e que, portanto, permaneciam agricultores pluriativos (com algum filho, ou a cônjuge, ocupada em alguma atividade não agrícola) - o "custo de saída" da atividade, uma vez que já tinham gasto um montante para edificar uma certa infra-estrutura. A despeito da dificuldade de auferir retornos remuneradores dos investimentos realizados, decorrente da instabilidade da atividade agrícola, e dos baixos recursos próprios para enfrentar os momentos adversos da atividade, a baixa escolaridade e o custo de abandonar a infra-estrutura montada (sem alternativas visíveis no horizonte do mercado de trabalho), explica a permanência de muitos dos entrevistados nas atividades agrícolas, não obstante as características de fragilização mostradas anteriormente. 
Constatou-se que 58,3\% das famílias - com até 10 hectares de terra - têm apenas 3 pessoas por família. Considerando que mais da metade $(53,0 \%)$ do total de pessoas com dez anos ou mais têm mais de 40 anos de idade e que os jovens não têm vontade de permanecer segundo declaração deles próprios - nas atividades agrícolas ${ }^{3}$, pode-se supor uma plausível tendência de maior redução do número dessas famílias, de modo que isso fragiliza ainda mais a perspectiva de crescimento de casos de pluriatividade das famílias. Porque, por um lado, embora os jovens queiram se envolver em atividades não agrícolas, por outro, os mais velhos irão naturalmente se tornar incapacitados de permanecer exercendo as atividades agrícolas. $\mathrm{O}$ progressivo abandono das atividades agrícolas desfaz, para as famílias em que esse processo ocorre, o elo agrícola da combinação, própria da pluriatividade, 'agrícola com não agrícola'. E o resultado, em muitos casos, poderá ser a conformação de famílias rurais de não ocupados (casal de aposentados com filhos residindo nas áreas urbanas) ou de famílias rurais não agrícolas (famílias com pelo menos um membro ocupado em alguma atividade não agrícola e nenhum outro ocupado em atividade agrícola).

Do ponto de vista das famílias pluriativas, deve-se ficar claro que tais famílias conciliam entre seus membros atividades agrícolas com atividades não agrícolas. Não existe pluriatividade sem o vínculo a uma atividade agrícola. Ou seja, a pluriatividade é constituída por dois vetores de determinação: um 'lado agrícola' e um 'lado não agrícola'. Na falta de um deles, a pluriatividade deixa de existir. Ora, os dados aqui comentados sugerem que não somente o 'lado não agrícola' deve ser fomentado, mas também o 'lado agrícola' deve ser protegido, valorizado, evitando o abandono das atividades agrícolas pelos pequenos produtores. Porque, sem apoio ao lado agrícola e esse vindo a sofrer reveses forçando pequenos produtores a abandoná-lo, o lado não agrícola, quanto mais dinâmico, e sem políticas que valorizem os pequenos produtores agrícolas, pode viabilizar a conversão de famílias agrícolas em famílias não agrícolas, e não em famílias pluriativas ${ }^{4}$.

A modernização significa, para muitos pequenos produtores familiares, exclusão do mercado (decorrente do acirramento da concorrência) ${ }^{5}$. Nesse caso, muitos deles ou permanecerão marginalizados na sua relação com a terra, ou se tornarão famílias não

\footnotetext{
3 Por diversas razões, por eles apontadas: por um lado, porque são atividades pesadas, e, especialmente, com baixíssimo retorno monetário; e, por outro lado, porque se sentem atraídos pelos atrativos urbanos (atividades não agrícolas, estudos, cultura em geral, rede de saúde etc.).

${ }^{4}$ Com isso não se está querendo contrapor - em termos de juízo de valor - um tipo de família a outro, se um é melhor do que outro. Apenas se está argumentando sobre o que pode favorecer o crescimento do contingente de um e de outro tipo familiar.

${ }^{5}$ Ver essa questão em Nascimento (2006; 2007; 2008).
} 
agrícolas, porque tenderão a abandonar a atividade agrícola que lhe passa a ser mais onerosa do que o contrário.

Por ficarem marginalizados do mercado (de integração aos circuitos comerciais e produtivos dos agronegócios), haverá sempre a tendência a abandonarem a atividade agrícola, sobretudo, tendo-se em vista alguns fatores que contribuem para essa decisão (forçada pelas circunstâncias), especialmente entre os jovens. Quais sejam: a) a difusão, através dos meios de comunicação de massa, dos hábitos e necessidades urbanos; b) a crescente dificuldade de manter uma atividade agrícola não remuneradora; c) conjunturas duradouras de crise no setor agrícola; d) entornos rurais (economias locais) dinâmicos, do ponto de vista não agrícola, proporcionando maiores oportunidades ocupacionais fora da agricultura; e) o descaso histórico do Estado no tocante ao amparo ao amplo conjunto dos pequenos produtores familiares.

Em muitas das entrevistas essas questões estiveram claramente presentes. Vários agricultores entrevistados relataram que se manter na atividade agrícola é muito arriscado e difícil, mas também o é sair dela, porque o custo de saída, assim como foi o de entrada (no caso, por exemplo, de alguns produtores de abacaxi do município), é elevado. Nessas condições, em muitos exemplos relatados, o endividamento vai se tornando uma "bola de neve" sem, contudo, saberem como enfrentá-lo satisfatoriamente. Esse é o contexto em que muitos dos entrevistados explicitaram que pretendem recorrer (porque já presenciaram exemplos semelhantes, de pessoas conhecidas no município) à ocupação em alguma atividade não agrícola como um primeiro passo - mais confiável - para ir aos poucos abandonando as atividades agrícolas, para, no fim do processo, tornarem-se famílias não agrícolas. Ou seja, vêem a pluriatividade como um processo apenas transitório, como uma etapa confiável na conversão de família agrícola para família não agrícola. Não porque não gostem das atividades agrícolas. Pelo contrário. A questão é que se sentem sem aquele apoio necessário - das políticas públicas - para continuarem insistindo em ser agricultores.

\section{CONSIDERAÇÕES FINAIS}

Colheu-se relatos diversos dos entrevistados a respeito do impacto que o avanço da cana-de-açúcar está provocando no município, e demais regiões circunvizinhas, em muitos casos forçando os pequenos produtores a arrendarem suas próprias terras, ou, para os casos de produtores não proprietários, não conseguirem arrendar terras de terceiros pela razão de que não conseguem competir com os preços de arrendamento pagos pelos produtores de 
cana. A conseqüência para esses produtores não proprietários é que terão que, se não quiserem abandonar as atividades agrícolas, recorrer ao arrendamento de terras em localidades mais distantes das que estavam acostumados, o que implica naturalmente em elevação de seus custos de produção. Ademais, foram também relatadas as dificuldades dos pequenos produtores - muitos deles animados com as possibilidades produtivas da modernização - a atenderem prontamente as exigências da modernização, em virtude do seu alto custo e do baixo retorno e pouco apoio estatal. O efeito desse quadro estrutural sobre a percepção dos jovens, filhos dos produtores familiares pesquisados, é o de que a agricultura não lhes promete possibilidade de reprodução social atrativa.

A ampliação, por exemplo, do alcance e recursos do PRONAF poderá ser uma importante alternativa de redução do que aqui retratamos como um quadro de "fragilidade" da agricultura familiar que a amostra utilizada representa. A diversificação, por exemplo, das modalidades de apoio do PRONAF, especialmente para os jovens, também pode ser uma forma importante de construção de capacidades (no sentido de SEN, 2000) para uma melhor inserção no mercado de trabalho não agrícola. Esses dois exemplos de vetores de ação podem contribuir para fortalecer a pluriatividade das unidades produtivas familiares, com todos os benefícios que a pluriatividade pode servir, conforme lhe atribui a literatura pertinente (SOUZA 2000; SCHNEIDER 2003; SACCO DOS ANJOS 2003; NASCIMENTO, 2006, 2008; entre outros).

\section{REFERÊNCIAS}

NASCIMENTO, C. A. Pluriatividade, pobreza pural e políticas públicas: uma análise comparada entre Brasil e União Européia. Fortaleza: Banco do Nordeste do Brasil, 2008.

NASCIMENTO, C. A. Pluriatividade e Políticas Públicas: o caso do Sul do Brasil. Revista de Economia Política, v. 27, p. 452-471, 2007.

NASCIMENTO, C. A. A dialética da pluriatividade: o caso do Sul do Brasil. In: XI ENCONTRO NACIONAL DE ECONOMIA POLÍTICA, 2006, Vitória. Anais... Vitória, 2006. 1 CD-ROM.

SACCO DOS ANJOS, F. A Agricultura familiar em transformação: o caso dos colonosoperários da Massaranduba, Santa Catarina. Pelotas: Editora da UFPel, 1994.

SCHNEIDER, S. Pluriatividade na agricultura familiar. Porto Alegre: Editora da UFRGS, 2003.

SEN, A. Desenvolvimento como liberdade. São Paulo: Companhia das Letras, 2000.

SOUZA, M. Atividades não-agrícolas e desenvolvimento rural no Estado do Paraná. Tese

(Doutorado em Engenharia Agrícola) - Faculdade de Engenharia Agrícola, Universidade Estadual de Campinas, 2000. 